\title{
Sigmund Freuds Kopf als Endloslinie
}

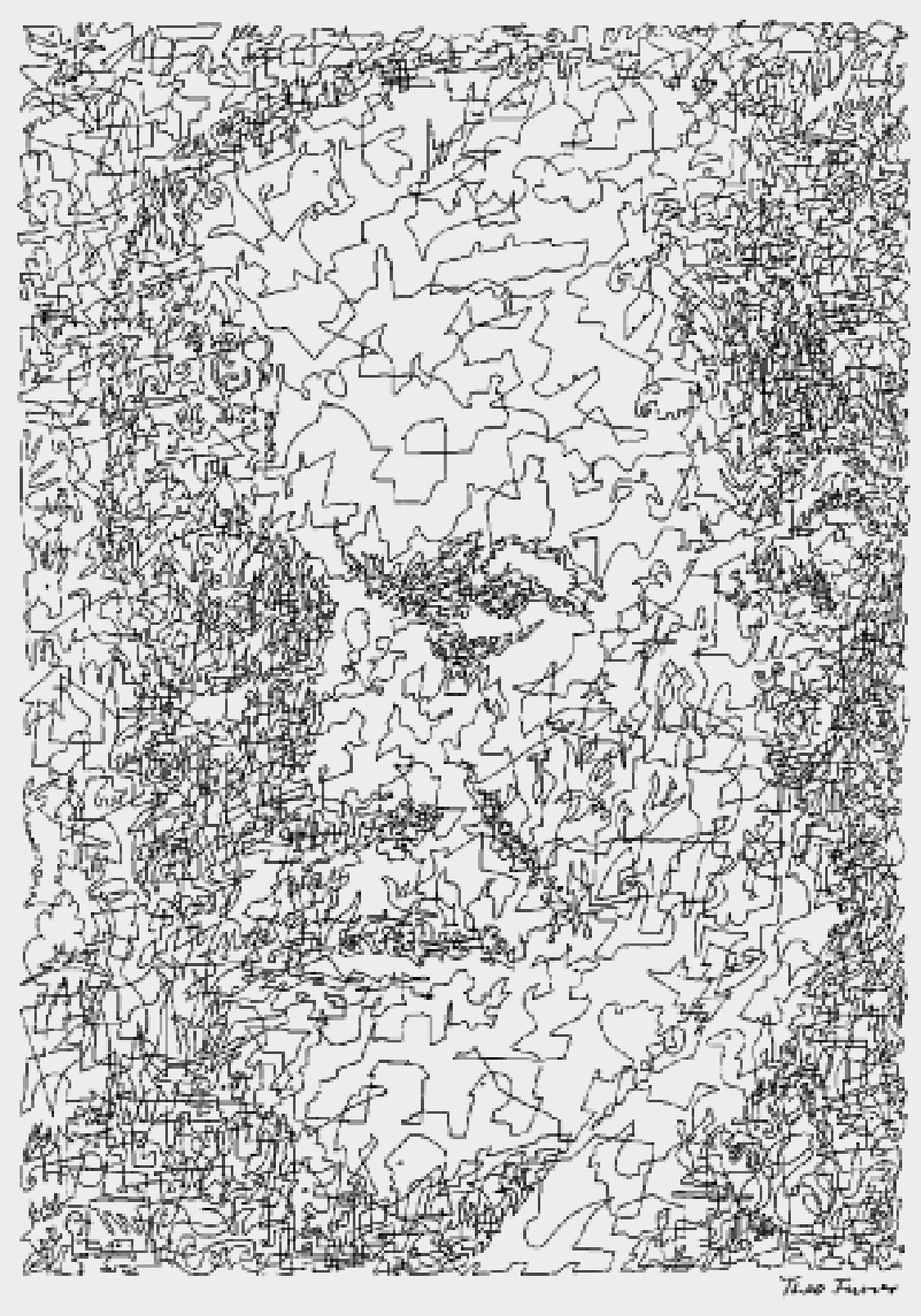

Der Künstler und Graphiker Theo Furrer präsentiert im zu Ende gehenden «Sigmund-FreudJahr» ein aussergewöhnliches Porträt des grossen medizinischen Pioniers. Das Werk ist in einer Zeichentechnik entstanden, die Furrer vor Jahren entwickelt hat und nach wie vor pflegt. Sie beruht auf Verdichtung und Auflösung der Linien. Die dabei spontan entstehenden, gegenständlichen und figurativen Anspielungen folgen dem Gesetz der freien Bildassoziation. So wird der Blick des Betrachters gleichsam von der Linie «geführt», und er hat doch die Freiheit, seine eigenen Bilder und Formkombinationen hineinzusehen und hineinzuinterpretieren. Dass das ganze Porträt aus einer einzigen, immer wieder in sich zusammenfallenden Endloslinie besteht, evoziert den Gedanken: «Alles ist mit allem verbunden.» Der Reiz und die Dynamik des Bildes besteht auch darin, dass beim näheren Betrachten das chaotisch anmutende Liniengewirr in sich Geschichten erzählt und erst mit zunehmendem Abstand zum Bild der Gesamtzusammenhang, also das Gesicht, zum Vorschein kommt.

Originalbild: $115 \times 155 \mathrm{~cm}$, schwarze Tusche auf Leinwand. Handsignierte Serigraphien $50 \times 65 \mathrm{~cm}$, numeriert, Auflage 75. 